\title{
Doenças de pele em equídeos no semiárido brasileiro ${ }^{1}$
}

\author{
André Flávio A. Pessoa ${ }^{2 *}$, Clarice Ricardo M. Pessoa², Eldinê G. Miranda Neto², \\ Antônio Flávio M. Dantas ${ }^{2}$ e Franklin Riet-Correa ${ }^{2}$
}

\begin{abstract}
Pessoa A.F.A., Pessoa C.R.M., Miranda Neto E.G., Dantas A.F.M. \& Riet-Correa F. 2014. [Skin disease of equidae in the Brazilian semiarid region.] Doenças de pele em equídeos no semiárido brasileiro. Pesquisa Veterinária Brasileira 34(8):743-748. Hospital Veterinário, CSTR, Universidade Federal de Campina Grande, Avenida Universitária s/n, Bairro Santa Cecília, Patos, PB 58708-110, Brazil. E-mail: andref_vet@hotmail.com

Diseases that affect the skin and appendages of equidae in the semiarid region of northeastern Brazil were analyzed through a retrospective study of records of the Large Animal Clinic of the Veterinary Hospital at the Federal University of Campina Grande, from January 2002 to December 2012. At all, 2054 equidae entered the hospital being 1786 horses, 200 donkeys, and 58 mules. A total of 535 (26.05\%) were affected by skin diseases, 447 horses, 68 donkeys and 20 mules. In horses the more prevalent skin diseases were pythiosis $(24.38 \%)$, traumatic injuries $(23.04 \%)$, abscesses $(12.75 \%)$, granulation tissue $(8.5 \%)$, and habronemiasis (7.38\%); together, these diseases represented $76 \%$ of dermatological problems observed in this species. In donkeys the more frequent diseases, representing $79.84 \%$ of the skin diseases, were traumatic wounds (47.5\%), sarcoid $(19.11 \%)$, and abscesses (13.23\%). In mules the most frequent disease was traumatic wounds (30\%) and habronemiasis and squamous cell carcinoma (15\% each), which together accounted for $60 \%$ of the skin diseases in this species. It is concluded that skin diseases are important in equidae in the semiarid region of northeastern Brazil and the knowledge generated in this work is important for the diagnosis and treatment of these diseases.
\end{abstract}

INDEX TERMS: Equine diseases, dermatology, skin desease, horses, donkeys, mules, equidae.

RESUMO.- As doenças que acometem a pele e anexos de equídeos no semiárido nordestino foram analisadas mediante um estudo retrospectivo dos registros de atendimento na Clínica de Grandes Animais do Hospital Veterinário da Universidade Federal de Campina Grande, de janeiro de 2002 a dezembro de 2012. Dos 2.054 atendimentos 1.786 eram equinos, 200 eram asininos e 58 eram muares. Os diagnósticos de dermatopatias totalizaram 535 casos $(26,05 \%)$ dos quais 447 foram em equinos, $68 \mathrm{em}$ asininos e 20 em muares. Nos equinos as dermatopatias mais frequentes foram a pitiose $(24,38 \%)$, as feridas traumáticas $(23,04 \%)$, os abscessos $(12,75 \%)$, o tecido de granulação $(8,5 \%)$ e a habronemose $(7,38 \%)$. Juntas essas enfermidades totalizaram $76,05 \%$ dos diagnósticos de dermatopatias para essa espécie. Em asininos as doenças mais frequen-

\footnotetext{
${ }^{1}$ Recebido em 15 de fevereiro de 2014.

Aceito para publicação em 7 de julho de 2014.

${ }^{2}$ Hospital Veterinário, Centro de Saúde e Tecnologia Rural (CSTR), Campus de Patos da Universidade Federal de Campina Grande (UFCG), Patos, PB 58700-970, Brasil. *Autor para correspondência: andref_vet@hotmail.com
}

tes foram feridas traumáticas $(47,5 \%)$, sarcoide $(19,11 \%)$ e abscessos $(13,23 \%)$. Estas enfermidades juntas representaram $79,84 \%$ das doenças de pele nesta espécie. Os muares apresentaram feridas traumáticas em $30 \%$ dos casos e carcinoma de células escamosas e habronemose em $15 \%$ cada. As três enfermidades representaram $60 \%$ dos diagnósticos de doenças de pele nesta espécie. Conclui-se que as doenças de pele são uma das principais causas de atendimento clínico em equídeos na região semiárida do nordeste do Brasil e os conhecimentos gerados neste estudo são importantes para o reconhecimento, diagnóstico e tratamento das mesmas.

TERMOS DE INDEXAÇ̃̃O: Doenças de equídeos, dermatologia, doenças da pele, equinos, asininos, muares, equídeos.

\section{INTRODUÇÃO}

A prática clínica em equinos tem sido alvo de constantes avanços nas últimas décadas e entre as especialidades a dermatologia é uma das que mais se destacam. Das espécies de produção, a equina é a mais comumente atendida 
por problemas dermatológicos (Lloyd et al. 2003, Scott e Miller Jr. 2011). Devido a similaridade no aspecto clínico de muitas dermatopatias, o diagnóstico final de problemas de pele em equinos frequentemente constitui um desafio ao clínico. Aliado a isso, pouco se sabe sobre as dermatopatias de asininos e muares. 0 objetivo deste estudo foi conhecer as enfermidades de pele e anexos de equídeos na região semiárida do Brasil. Para isso foi determinada a frequência e as características clínicas e epidemiológicas das doenças de pele diagnosticadas no Hospital Veterinário (HV) da Universidade Federal de Campina Grande (UFCG).

\section{MATERIAL E MÉTODOS}

Foram revisadas as fichas clínicas de equídeos que apresentavam enfermidades envolvendo a pele e anexos no período de janeiro de 2002 a dezembro de 2012, arquivadas na Clínica de Grandes Animais do Hospital Veterinário da Universidade Federal de Campina Grande (HV/UFCG). Dados referentes à identificação e anamnese do animal, exame físico, protocolo de tratamento e evolução dos casos foram resgatados das fichas clínicas de cada equídeo atendido. Os laudos histopatológicos de biópsias e necropsias foram obtidos no Laboratório de Patologia Animal (LPA) da UFCG. Os diagnósticos foram realizados mediante observação dos sinais clínicos, histopatologia, cultura microbiológica, tricograma, citologia e exame direto de raspados cutâneos, e diagnóstico terapêutico. Foram obtidos os dados epidemiológicos de cada caso (raça, sexo, idade, época do ano de ocorrência da doença, forma de criação e tratamento realizado). Quanto ao sexo, os animais foram classificados como macho, independentemente de serem castrados ou não, ou fêmea. As estações do ano foram divididas em duas: de janeiro a junho, estação chuvosa; e de julho a dezembro, estação seca, de acordo com Pessoa et al. 2012.

\section{RESULTADOS}

Durante o período analisado foram realizados 2.054 atendimentos de equídeos na Clínica de Grandes Animais do HV/UFCG, desses 1.786 eram equinos, 200 asininos e 58 muares. Dentre todos os atendimentos as dermatopatias totalizaram 535 (26,05\%); afetando 25,03\% (447/1786) dos equinos, 34\% (68/200)dos asininos e 34,48\% (20/58) dos muares. 0 número de casos por espécie e a prevalência de cada doença encontram-se no Quadro 1. No Quadro 2 observa-se a localização das lesões de pitiose, habronemose, carcinoma de células escamosas e tecido de granulação exuberante. No Quadro 3 observam-se as doenças que apresentaram distribuição sazonal.

A doença infecciosa mais frequente neste estudo foi a pitiose (Fig.1A). Dos 110 animais acometidos 12 foram eutanasiados, nove após insucesso do tratamento e três sem tratamento devido à gravidade das lesões. Os tratamentos empregados foram: cirurgia (103 casos/6 mortes), curetagem ( 4 casos $/ 0$ mortes) e a associação entre tratamento cirúrgico e uso de imunoterápicos (1 caso/1 óbito) ou iodeto de potássio ( 2 casos/2 mortes). A localização das lesões de pitiose e outras enfermidades que devem ser consideradas no diagnóstico diferencial desta doença encontram-se no Quadro 2. Os casos de pitiose foram atendidos durante todo o ano (Fig.2).

Os 66 abscessos diagnosticados (Quadro 1) tiveram localização variada: 28 na cernelha; 17 nos membros; 14 no pescoço; quatro na região do dorso; e três na nuca. Nenhum dos animais com abscesso de cernelha apresentou sorologia positiva para brucelose. Em três desses casos foi realizada cultura microbiológica sendo isolado Staphyloccocus spp.

Quadro 1. Afecções de pele de equídeos diagnosticadas na Clínica de Grandes Animais do Hospital Veterinário, Universidade Federal de Campina Grande, de janeiro de 2002 a dezembro de 2012

\begin{tabular}{|c|c|c|c|c|c|c|c|c|}
\hline \multirow[t]{2}{*}{ Diagnóstico } & \multirow[t]{2}{*}{$\mathrm{N}$} & \multirow[t]{2}{*}{$\%$} & \multicolumn{6}{|c|}{ Espécie } \\
\hline & & & Equina & $\%$ & Asinina & $\%$ & Muar & $\%$ \\
\hline Feridas traumáticas & 141 & 26,35 & 103 & 23,04 & 32 & 47,06 & 6 & 30 \\
\hline Pitiose & 110 & 20,56 & 109 & 24,38 & - & - & 1 & 5 \\
\hline Abscessos & 66 & 12,33 & 57 & 12,75 & 9 & 13,23 & - & \\
\hline Sarcoide & 39 & 7,28 & 24 & 5,37 & 13 & 19,12 & 2 & 10 \\
\hline $\mathrm{TGE}^{\mathrm{a}}$ & 39 & 7,28 & 38 & 8,50 & 1 & 1,48 & - & \\
\hline Habronemose & 36 & 6,72 & 33 & 7,38 & - & - & 3 & 15 \\
\hline Sinus & 24 & 4,48 & 19 & 4,25 & 3 & 4,41 & 2 & 10 \\
\hline Dermatofitose & 19 & 3,55 & 15 & 3,35 & 4 & 5,88 & - & - \\
\hline Carcinoma de células escamosas & 18 & 3,36 & 15 & 3,35 & - & - & 3 & 15 \\
\hline Dermatite alérgica & 11 & 2,05 & 10 & 2,24 & 1 & 1,47 & - & - \\
\hline Miíase & 6 & 1,12 & 4 & 0,89 & 2 & 2,94 & - & - \\
\hline Fotossensibilização primária & 6 & 1,12 & 5 & 1,12 & 1 & 1,47 & - & - \\
\hline Dermatofilose & 5 & 0,93 & 4 & 0,89 & 1 & 1,47 & - & - \\
\hline Papiloma & 4 & 0,74 & 4 & 0,89 & - & - & - & - \\
\hline Melanoma & 3 & 0,56 & 3 & 0,67 & - & - & - & - \\
\hline Pênfigo & 2 & 0,37 & 2 & 0,44 & - & - & - & - \\
\hline Hemangiossarcoma & 1 & 0,18 & 1 & 0,22 & - & - & - & - \\
\hline Hemangiopericitoma & 1 & 0,18 & - & - & - & - & 1 & 5 \\
\hline Fibrossarcoma & 1 & 0,18 & - & - & - & - & 1 & 5 \\
\hline Hiperplasia de torus metacarpiano & 1 & 0,18 & 1 & 0,22 & - & - & - & - \\
\hline Dermatose solar & 1 & 0,18 & - & - & - & - & 1 & 5 \\
\hline Ectoparasitismo por piolho & 1 & 0,18 & - & - & 1 & 1,47 & - & - \\
\hline Total & 535 & & 447 & 100 & 68 & 100 & 20 & 100 \\
\hline
\end{tabular}

aTGE = tecido de granulação exuberante. 
Quadro 2 . Localizações das lesões proliferativas diagnosticadas na Clínica de Grandes Animais do Hospital Veterinário, Universidade Federal de Campina Grande, de janeiro de 2002 a dezembro de 2012

\begin{tabular}{lccccc}
\hline \multicolumn{1}{c}{ Localização } & \multicolumn{5}{c}{ Enfermidade } \\
\cline { 2 - 6 } & Pitiose & Sarcoide & Habronemose & CCE $^{\mathrm{a}}$ & TGE $^{\mathrm{b}}$ \\
\hline Membros & 47 & 14 & 8 & - & 32 \\
Tórax & 8 & 2 & - & - & 1 \\
Abdômen & 26 & 3 & - & - & 1 \\
Cabeça & 5 & 10 & 19 & 10 & 2 \\
Órgãos reprodutores & 4 & 4 & - & 4 & - \\
Pescoço & 1 & 1 & - & - & - \\
Múltipla & 12 & 4 & 9 & 4 & - \\
NIc & 7 & 1 & - & - & 3 \\
Total & 110 & 39 & 36 & 18 & 39
\end{tabular}

${ }^{\mathrm{a}} \mathrm{CCE}=$ carcinoma de células escamosas, ${ }^{\mathrm{b}} \mathrm{TGE}$ = tecido de granulação exuberante, ${ }^{\mathrm{c}} \mathrm{NI}=$ Não informado.

Quadro 3. Dermatopatias diagnosticadas na Clínica de Grandes Animais do Hospital Veterinário, Universidade Federal de Campina Grande, de janeiro de 2002 a dezembro de 2012 com distribuição sazonal

\begin{tabular}{lcc}
\hline \multirow{2}{*}{\multicolumn{1}{c}{ Diagnóstico }} & \multicolumn{2}{c}{ Estação } \\
\cline { 2 - 3 } Dermatofitose & Chuvosa & Seca \\
\hline Dermatofilose & $100 \%(5 / 5)$ & $18,75 \%(3 / 16)$ \\
Dematite alérgica & $100 \%(11 / 11)$ & - \\
Fotossensibilização primária & $100 \%(6 / 6)$ & - \\
Habronemose & $66,66 \%(24 / 36)$ & $33,34 \%(12 / 36)$ \\
Miíase & $100 \%(6 / 6)$ & -
\end{tabular}

Dos 24 casos de sinus (abscessos associados a corpos estranhos), 14 casos foram tratados cirurgicamente e consistiam de fragmentos de arame ou madeira; os demais foram tratados com drenagem e curetagem do conteúdo e uso de antibiótico tópico.

A maioria dos casos de dermatofitose (13/16) foi diagnosticada na estação chuvosa, no entanto, dos três casos diagnosticados na estação seca, em dois os sinais iniciaram na estação chuvosa (Quadro 3). Clinicamente os animais apresentavam múltiplas áreas alopécicas planas com prurido discreto e as lesões concentravam-se na base da crina e cauda, na cabeça e no dorso. Foram diagnosticados cinco casos de dermatofilose, todos na estação chuvosa; as lesões, mais frequentes no dorso, caracterizavam-se por crostas das quais se desprendiam tufos de pêlos após leve tração. Nos casos de dermatofitose o tratamento foi realizado pelo uso tópico de iodo-polvidine (degermante) durante 7-14 dias, na dermatofilose além do tratamento tópico foram utilizados antibióticos sistêmicos a base de penicilina.

Papilomatose foi observada em quatro animais que apresentaram múltiplas verrugas localizadas principalmente na face, pênis ou base da cauda e o tratamento foi realizado mediante procedimento cirúrgico.

Habronemose (Fig.1B) foi a dermatite parasitária mais frequente e com maior importância para muares (Quadro $1)$. Considerando as duas espécies acometidas, muares e equinos, 66,66\% dos casos da enfermidade foram diagnosticados na estação chuvosa. A lesão consistia de tecido proliferativo e ulcerado, frequentemente encontrada na comissura labial e medial dos olhos, e porções distais dos

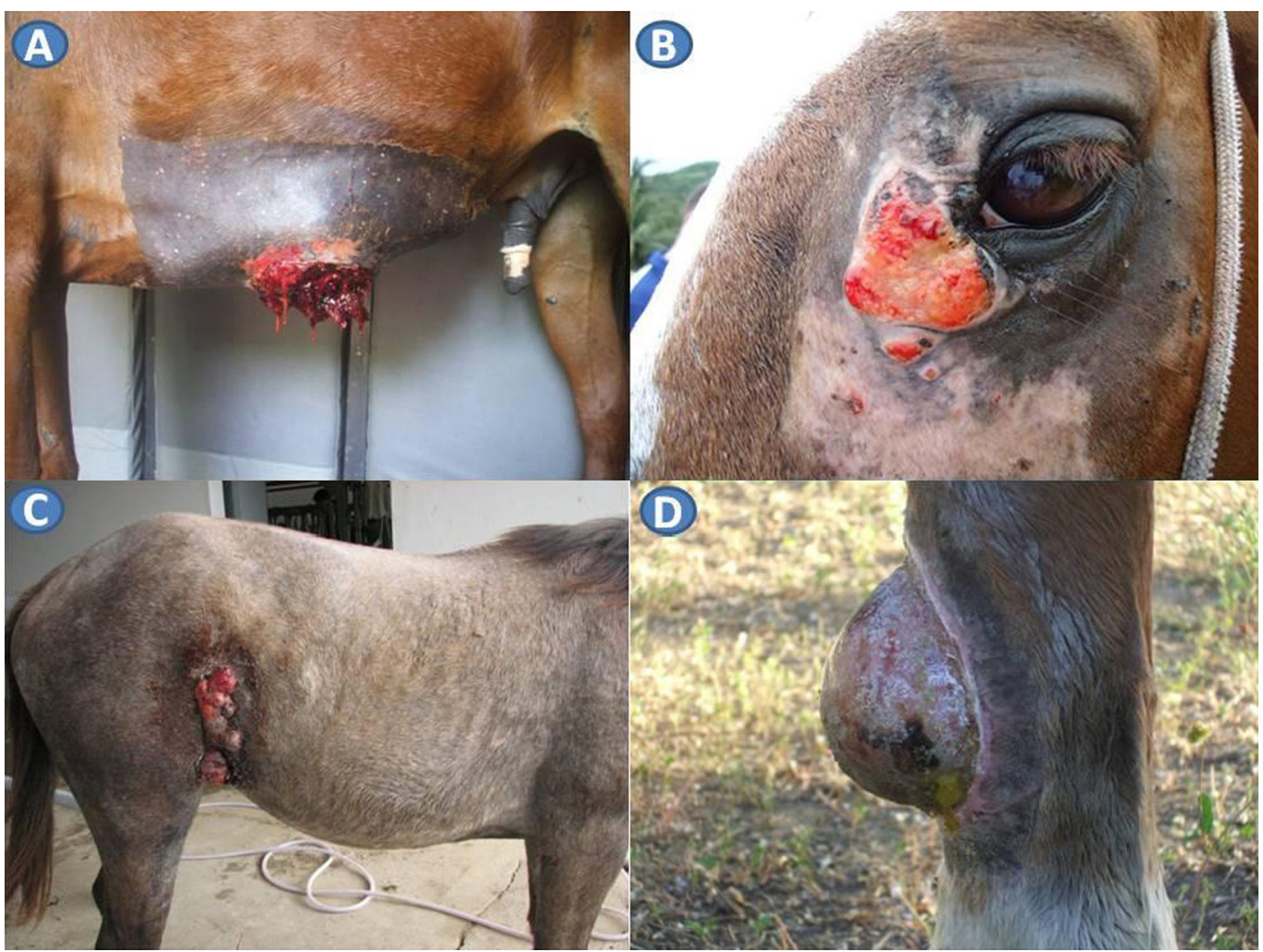

Fig.1. (A) Pitiose no abdômen. (B) Habronemose na comissura ocular medial esquerda.(C) Sarcoide na região do flanco direito. (D) Tecido de granulação exuberante no metacarpo esquerdo. 


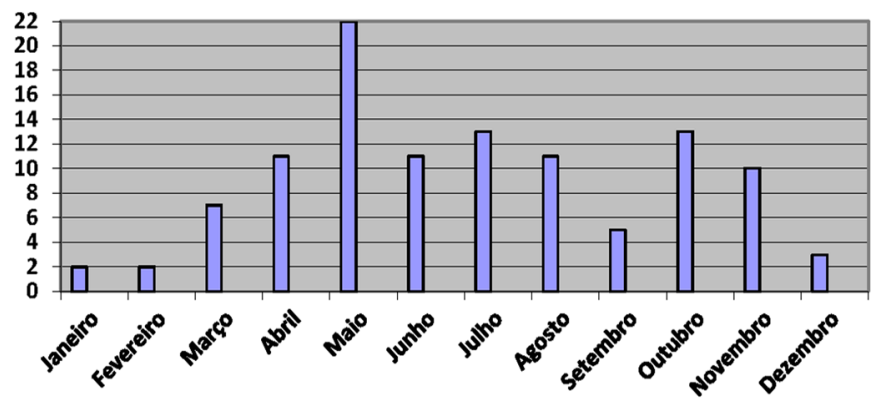

Fig.2. Distribuição dos casos de pitiose diagnosticados na Clínica de Grandes Animais do HV/UFCG, de 2002 a 2012, nos diferentes meses do ano.

membros (Quadro 2). Em 26 dos 36 casos houve boa resposta ao tratamento tópico de triclorfon ${ }^{3}$ e administração oral de endectocida à base de ivermectina ${ }^{4}$. Em apenas 10 casos foi necessária a associação entre o tratamento cirúrgico e o clínico.

As miíases foram verificadas na estação chuvosa. Em dois dos seis casos estiveram associadas à fístula perianal. 0 único diagnóstico de ectoparasitismo foi devido a infestação por piolho (Damalinia equi) em um asinino.

Das neoplasias, o sarcoide (Fig.1C) foi mais frequente (39 casos). Os asininos foram os mais acometidos. A distribuição mais comum foi nos membros e na cabeça (Quadro 2) e em $87,18 \%$ dos casos o animal apresentava um único tumor. Em todos os casos o tratamento empregado foi a ressecção cirúrgica. Durante o período analisado, 18 casos de carcinomas de células escamosas foram diagnosticados em 15 equinos e três muares, sendo 10 localizados na cabeça, quatro em órgãos genitais e quatro com localização múltipla (Quadro 2). Em um trabalho prévio foram descritas as principais localizações e os fatores de risco associados a ocorrência de carcinoma de células escamosas em equinos no semiárido da Paraíba (Carvalho et al. 2012). Três casos de melanoma foram identificados em equinos de pelagem tordilha; dois animais foram submetidos a cirurgia, um desses com localização perianal foi eutanasiado pois a lesão invadia o reto. Os outros dois receberam alta, um deles sem receber nenhum tratamento por opção do proprietário. Outros tumores foram, também, diagnosticados em uma oportunidade cada: hemangiossarcoma, hemangiopericitoma e fibrossarcoma. Um equino foi atendido com hipertrofia de torus metacarpiano. Foram realizados procedimentos cirúrgicos nestes quatro animais e todos receberam alta.

Nos 11 casos de dermatite alérgica o diagnóstico foi realizado pela epidemiologia e achados clínicos. Dez casos tiveram diagnóstico clínico e terapêutico. Em um caso foi realizada biópsia e o laudo histopatológico revelou dermatite perivascular superficial eosinofílica. Os sinais clínicos consistiam em áreas de prurido intenso, alopecia e presença de crostas nas regiões de peito e pescoço e em três casos abdômen ventral e membros. Todos os animais afetados eram jovens menores de 5 anos e todos os casos ocorreram durante a estação chuvosa (Quadro 3).

\footnotetext{
${ }^{3}$ Neguvon $^{\circledR}$ - Bayer saúde animal, Brasil.

${ }^{4}$ Handicap pasta ${ }^{\circledR}$ - Marcolab Laboratórios Ltda, Brasil.
}

Foram observados dois casos de pênfigo foliáceo em equinos da raça Quarto de Milha, com idade de dois e seis anos, respectivamente. Clinicamente os animais apresentavam múltiplas placas crostosas com bordos elevados, apresentando de hipotricose a alopecia. As lesões eram não pruriginosas e tinham distribuição generalizada. 0 animal de dois anos apresentava edema na porção ventral do abdômen e membros. No exame histológico na epiderme havia pústulas subcorneais com células acantolíticas e presença de espongiose e exocitose. Na derme superficial havia infiltrado neutrofílico perivascular. A enfermidade foi controlada pelo uso de corticóides e os animais receberam alta.

Feridas traumáticas totalizaram 26,35\% (141/535) dos casos (Quadro 1). Em 45 casos as feridas foram reparadas cirurgicamente através do fechamento primário e nas demais, devido à contaminação, optou-se pelo reparo tardio ou cicatrização por segunda intenção. Esta foi a principal causa de atendimentos de asininos e muares neste estudo. 0 Tecido de granulação exuberante (Fig.1D) decorrente de traumas foi diagnosticado em 39 casos $(7,28 \%)$, apresentando maior importância para equinos (Quadros 1 e 2).

Seis diagnósticos de fotossensibilização primária foram realizados, todos durante a estação chuvosa (Quadro 3). Os animais apresentavam lesões eritematosas e ulcerativas em áreas despigmentadas do corpo e expostas ao sol, normalmente na face e extremidades distais dos membros. Os animais eram criados com acesso a pastagem nativa e não tinham indicativos de insuficiência hepática. Houve suspeita de dermatose solar em um muar albino que apresentava lesões crostosas e eritematosas nos bordos das orelhas e ao redor dos olhos. Nos casos de fotossensibilização primária e no de dermatose solar, foi indicado o uso de pomadas cicatrizantes e a manutenção dos animais em locais protegidos do sol.

As enfermidades de pele que pela gravidade (extensão e localização) determinaram a eutanásia foram pitiose $(12 / 110)$, carcinoma de células escamosas $(6 / 18)$ e melanoma $(1 / 3)$.

\section{DISCUSSÃO}

Os resultados do levantamento demonstram que as dermatopatias mais frequentemente diagnosticadas em equídeos no semiárido foram: pitiose, feridas traumáticas e abscessos em equinos; feridas traumáticas, sarcoide e abscessos em asininos e feridas traumáticas, carcinoma de células escamosas e habronemose em muares. Pitiose foi a doença de pele observada com maior frequência em equinos, representando 24,38\% dos diagnósticos. Em estudos realizados no Rio Grande do Sul, a prevalência desta enfermidade foi de $14,34 \%$ entre todas as doenças de pele observadas (Marcolongo-Pereira et al. 2012) e 8,3\% das lesões tumoriformes observadas nesta espécie (Souza et al. 2011). A distribuição dos casos de pitiose durante os meses do ano e o número e localização das lesões encontradas neste estudo foram semelhantes às encontradas em equinos e muares no semiárido da Paraíba por Tabosa et al. (1999) e em equinos por Marcolongo-Pereira et al. (2012) no Rio Grande do Sul, confirmando que a pitiose ocorre durante todo ano e apresenta mais frequentemente lesões únicas, localizadas 
principalmente nas porções distais dos membros e na região ventral do abdômen.

No semiárido nordestino consideram-se como fatores predisponentes da pitiose cutânea, rinofacial e digestiva em ovinos (Tabosa et al. 2004, Pessoa et al. 2012) e cutânea em equinos (Tabosa et al. 1999) a presença de água estagnada (reservatórios de água a ser utilizada nos períodos de estiagem), a alta temperatura da água, que favorece a proliferação da forma infectante do agente e a escassez de forragens na estação seca, que leva os animais a se alimentarem com plantas aquáticas presentes nos reservatórios. Neste estudo verificou-se a presença da enfermidade durante todo o ano, dessa forma a escassez de forragem não parece ser um fator tão importante para o desenvolvimento da enfermidade em equinos tanto quanto é para ovinos (Tabosa et al. 2004, Pessoa et al. 2012). Aparentemente para equinos outro fator que deve ser considerado é o comportamento animal. No semiárido, assim como em outras regiões do Brasil, é comum observar equinos manterem-se por longos períodos do dia dentro dos açudes, possivelmente buscando conforto térmico além de fonte de alimento. Os asininos, ao contrário dos equinos, preferem ambientes secos e evitam a permanência em áreas alagadas. Provavelmente a ausência de relatos de pitiose em asininos esteja associada com esse fator comportamental.

Neste levantamento as feridas traumáticas representaram $26,35 \%$ dos atendimentos de equídeos envolvendo a pele, sendo mais frequente em muares $(47,06 \%)$ e asininos (30\%) do que em equinos $(23,04 \%)$. Num estudo retrospectivo realizado no Rio Grande do Sul, a prevalência de feridas traumáticas em equinos foi de $37 \%$ (Paganela et al. 2009). Essa é uma afecção frequente, cosmopolita e normalmente a mais prevalente em regiões geográficas onde equídeos são utilizados para o trabalho, especialmente em países em desenvolvimento (Knottenbelt 2005). No presente estudo as feridas traumáticas não tiveram predileção por idade, sexo ou tipo de manejo, mas afetaram especialmente animais de tração, que é o principal tipo de atividade dos asininos e muares atendidos no HV/UFCG.

Entre as enfermidades mais importantes para equinos, três devem ser diferenciadas entre si: pitiose, sarcoide e habronemose e estas devem ser diferenciadas do tecido de granulação exuberante. As localizações do tecido de granulação exuberante, pitiose e sarcoide foram mais frequentes nos membros, $82,05 \%, 42,72 \%$ e $35,9 \%$ respectivamente, enquanto que a habronemose foi mais frequente na cabeça $(52,77 \%)$. 0 presente estudo demonstrou que na região semiárida assim como em outras partes do mundo, existe sazonalidade na ocorrência de habronemose, que é mais frequente na estação das chuvas, na qual há aumento da população dos hospedeiros intermediários e vetores, a mosca dos estábulos (Stomoxys calcitrans) e a mosca doméstica (Musca domestica) (Thomassian 2005).

As neoplasias com maior número de diagnósticos nos equídeos foram o sarcoide $(57,35 \%, 39 / 68)$ e o carcinoma de células escamosas $(24,47 \%, 18 / 68)$. Esses dados são semelhantes aos encontrados na literatura nacional e internacional para a prevalência de neoplasias cutâneas em equinos (Valentine 2006, Ramos et al. 2008, Scott e Miller Jr.
2011, Souza et al. 2011, Carvalho et al. 2012). Sarcoide foi a única neoplasia diagnosticada em asininos com frequência maior do que a observada em equinos. Alta incidência de sarcoide em asininos e muares já havia sido descrita (Reidet al. 1994, Valentine 2006). Os achados desse estudo são semelhantes aos de White (2013), que descreve maior incidência de sarcoide em asininos do que em equinos, devido provavelmente a uma maior predisposição dessa espécie.

Os casos de fotossensibilização identificados neste estudo provavelmente estiveram associados ao consumo de Froelichia humboltidiana, pois de acordo com Pimentel et al. (2007) esta é a única causa de fotossensibilização primária em equinos descrita no semiárido. Não foi possível determinar se os animais deste estudo consumiram essa planta ou outra ainda desconhecida com os mesmos efeitos, mas pelos dados do estudo a doença acometeu animais que eram criados em sistema extensivo ou semi-extensivo tendo acesso a pastagens com plantas nativas na época chuvosa, período em que alguns pastos da caatinga apresentam F. humboltidiana em abundância. Embora a intoxicação crônica por alcaloides pirrolizidínicos associada ao consumo Crotalaria retusa (Pimentel et al. 2009) seja uma das doenças mais frequentes de equinos no semiárido, os principais sinais clínicos em equinos são de encefalopatia hepática e raramente apresentam fotossensibilização secundária como parte da síndrome de insuficiência hepática.

É possível que os casos de dermatite alérgica por picada de insetos descritos neste estudo tenham sido ocasionados por hipersensibilidade a culicoides. Em todo o mundo o gênero Cullicoides é o principal relacionado com essa condição e no Brasil a enfermidade já foi descrita em ovinos (Souza et al. 2005, Corrêa et al. 2007, Barbosa et al. 2011, Portela et al. 2012) e equinos (Portugal et al. 1996, Schild et al. 2003). A presença do gênero no semiárido já foi relatada inclusive associada à dermatite alérgica em ovinos (Araújo Lima et al. 2004, Portela et al. 2012). As principais características a serem observadas para o diagnóstico de dermatite alérgica a picada de insetos são o prurido intenso, o caráter sazonal e a presença de ambiente adequado para a proliferação dos insetos (White e Yu 2006). A localização das lesões pode ser variada dependendo do inseto envolvido (Rees 2005). Normalmente os sinais iniciam quando os animais são jovens, de 2-4 anos (Scott e Miller Jr. 2011) semelhante ao que foi visto neste estudo.

Neste estudo, pênfigo foliáceo foi diagnosticado em duas ocasiões. Pênfigo foliáceo faz parte de um complexo de enfermidades autoimunes caracterizada por perda da aderência dos ceratinócitos da epiderme e, embora pouco comum em equinos, é a principal enfermidade autoimune nesta espécie. Pênfigo vulgar e pênfigo paraneoplásico são outras enfermidades do complexo que já foram diagnosticadas em equinos; no entanto são extremamente raras (Stannard 2000). Nos EUA pênfigo foliáceo tem sido uma enfermidade frequentemente diagnosticada em equinos, representando 1,85\% das dermatopatias (Scott e Miller Jr. 2011). No Brasil apenas dois casos foram relatados (Oliveira Filho et al. 2007, Monteiro et al. 2007). As lesões de pênfigo geralmente são exfoliativas, crostosas e normalmente iniciam-se na face e membros e espalham-se por todo o corpo (White 
2003, Fadok 1995). A presença de prurido, dor e edema são variáveis (White e Yu 2006). Para o diagnóstico das diferentes formas de pênfigo a avaliação histopatológica é imprescindível, observando-se vesículas ou pústulas intraepidérmicas com células acantolíticas (Ginnet al. 2007).

\section{CONCLUSÕES}

Com base nos achados deste estudo pode se concluir que as dermatopatias são uma importante causa de atendimentos em equídeos no semiárido Brasileiro, representando $26,05 \%$ dos casos.

As enfermidades mais frequentes no período analisado foram pitiose em equinos e feridas traumáticas em asininos e muares.

São observadas, também, altas frequências de sarcoide em asininos e carcinoma de células escamosas e habronemose em muares. Dessas cinco enfermidades apenas habronemose apresentou caráter sazonal, ocorrendo com maior frequência em época chuvosa, enquanto que as demais foram verificadas durante todo o ano.

Os conhecimentos gerados neste trabalho podem colaborar na capacitação dos médicos veterinários para o conhecimento e diferenciação das principais dermatopatias de equídeos na região semiárida do Brasil.

\section{REFERÊNCIAS}

Araújo Lima R.C., Almeida V.F. \& Athayde A.C. 2004. Ocorrência de Culicoides furens (Diptera: Ceratopogonidae) no município de Lagoa Seca, Paraíba. XXXI Congresso Brasileiro de Medicina Veterinária, São Luis, Maranhão.

Barbosa J.D., Albernaz T.T., Oliveira C.M.C., Duarte M.D., Oliveira C.H.S., Brito M.F. \& Silva A.G.M. 2011. Dermatite alérgica à picada de insetos em ovinos no estado do Pará. Pesq. Vet. Bras. 31(2):117-120.

Corrêa T.G., Ferreira J.M., Riet-Correa G., Ruas J.L., Schild A.L., Riet-Correa F., Guimarães A. \& Felippe-Bauer M.L. 2007. Seasonal allergic dermatitis in sheep in southern Brazil caused by Culicoides insignis (Diptera: Ceratopogonidae). Vet. Parasitol. 145(1/2):181-185.

Carvalho F.K.L., Dantas A.F.M., Riet-Correa F., Miranda Neto E.G., Simões S.V.D. \& Azevedo S.S. 2012. Fatores de risco associados à ocorrência de carcinoma de células escamosas em ruminantes e equinos no semiárido da Paraíba. Pesq. Vet. Bras. 32(9):881-886.

Fadok V.A. 1995. An overview of equine dermatoses characterized by scaling and crusting. Vet. Clin. North Am., EquinePract. 11(1):43-51.

Ginn P.E., Mansell J.E.K.L. \& Rakich P.N. 2007. Skin and appendages, p.556780. In: Jubb K.V.F., Kennedy P.C. \& Palmer N.C. (Eds), Pathology of Domestic Animals. Vol.2. $5^{\text {th }}$ ed. Academic Press, San Diego.

IBGE 2012. Produção da Pecuária Municipal (PPM). Vol.39. Instituto Brasileiro de Geografia e Estatística, Rio de Janeiro, RJ. 63p.

Knottenbelt D.C. 2005. Skin disorders of donkeys. In: Matthews N.S. \& Taylor T.S. (Eds), Veterinary Care of Donkeys. International Veterinary Information Service, Itjhaca. (www.ivis.org), Document No. A2918.0605.<http://www.ivis.org/advances/Matthews/knottenbelt/ chapter.asp?LA=1> Accessed 24 Nov. 2013.

Lloyd D.H., Littlewood J.D., Craig J.M. \& Thomsett L.R. 2003. Practical Equine Dermatology. Blackwell Science, Iowa, p.63-99.

Marcolongo-Pereira C., Sallis E.S.V., Raffi M.B., Pereira D.I.B., Hinnah F.L., Coelho A.C.B. \& Schild A.L. 2012. Epidemiologia da pitiose equina na Região Sul do Rio Grande do Sul. Pesq. Vet. Bras. 32(9):865-868.
Monteiro G.A., Souza M.V., Conceição L.G., Borba C.L.B.R. \& Moreira M.A.S. 2007. Pênfigo foliáceo em um equino. Ciência Rural. 37(2):594-598.

Oliveira Filho J.P., Gonçalves R.C., Chiacchio S.B., Amorim R.M., Conceição L.G. \& Borges A.S. 2007. Pênfigo foliáceo em equino: relato de caso. Arq. Bras. Med. Med. Vet. Zootec. 59(5):1132-1136.

Paganela J.C., Ribas L.M., Santos C.A., Feijó L.S., Nogueira C.E.W. \& Fernandez C.G. 2009. Abordagem clínica de feridas cutâneas em equinos. Rev. Port. Ciênc. Vet. 104(569/572):13-18.

Pessoa A.F.A., Miranda Neto E.G., Pessoa C.R.M., Simões S.V.D., Azevedo S.S. \& Riet-Correa F. 2012. Abdômen agudo em equídeos no semiárido do Nordeste do Brasil. Pesq. Vet. Bras. 32(6):503-509.

Pessoa C.R.M., Riet-Correa F., Pimentel L.A., Garino Jr F., Dantas A.F.M., Kommers G.D., Tabosa I.M. \& Reis-Júnior J.L. 2012. Pythiosis of the digestive tract in sheep. J. Vet. Diagn. Invest. 24(6):1133-1136

Pimentel L.A., Oliveira D.M., Galiza G.J.N., Rego R.O., Dantas A.F.M. \& Riet-Correa F. 2009. Doenças do sistema nervoso central de equídeos no semi-árido. Pesq. Vet. Bras. 29(7):589-597.

Pimentel L.A., Riet-Correa F., Guedes K.M., Macêdo J.T.S.A., Medeiros R.M.T. \& Dantas A.F.M. 2007. Fotossensibilização primária em equídeos e ruminantes no semi-árido causada por Froelichia humboldtiana (Amaranthaceae). Pesq. Vet. Bras. 27(1):23-28.

Portela R.A., Carvalho K.S., Ahid S.M.M., Felippe-Bauer M.L. \& Riet-Correa F. 2012. Dermatite alérgica sazonal em ovinos deslanados no Nordeste do Brasil. Pesq. Vet. Bras. 32(6):471-476.

Portugal M.A.S.C., Guerra J.L., Baldassi L., Fernadez N.S. \& Calil E.M.B. 1993. Dermatite estival recidivante em equinos. Arq. Inst. Biológico, São Paulo. 63(1):1-6.

Ramos A.T., Souza A.B., Norte D.M., Ferreira J.L.M. \& Fernandes C.G. 2008. Tumores em animais de produção: aspectos comparativos. Ciência Rural. 38(1):148-154.

Rees C. 2005 Diagnosing and managing equine pruritus: insect hypersensitivity. Compend. Cont. Educ. Pract. Vet. 27:629-636.

Reid S.W., Gettinby G., Fowler J.N. \& Ikin P. 1994. Epidemiological observations on sarcoids in a population of donkeys (Equus asinus). Vet. Rec. 134:207-211.

Schild A.L., Ferreira J.L. \& Soares M.P. 2003. Boletim no23 do Laboratório Regional de Diagnóstico. Editora e Gráfica Universitária UFPEL, Pelotas RS.40p.

Scott D.W. \& Miller Jr W.H. 2011. Equinedermatology. W.B. Saunders, St Louis. 536 p.

Souza T.M., Brum J.S., Fighera R.A., Brass K.E. \& Barros C.S.L. 2011. Prevalência dos tumores cutâneos de equinos diagnosticados no Laboratório de Patologia Veterinária da Universidade Federal de Santa Maria, Rio Grande do Sul. Pesq. Vet. Bras. 31(5):379-382.

Souza T.M., Fighera R.A., Piazer J.V., Irigoyen L.F. \& Barros C.S.L. 2005. Dermatite alérgica sazonal em ovinos. Ciência Rural 35(2):475-477.

Stannard A.A. 2000. Immunologic diseases. Vet. Dermatol. 11:163-178.

Tabosa I.M., Medeiros V.T., Dantas A.F.M., Azevedo E.O. \& Maia J.C. 1999. Pitiose cutânea em equinos no semi-árido da Paraíba. Arq. Bras. Med. Vet. Zootec. 51(1):27-30.

Tabosa I.M., Medeiros V.T., Dantas A.F.M., Azevedo E.O. \& Maia J.C. 2004. Outbreaks of pythiosis in two flocks of sheep in Northeastern Brazil. Vet. Pathol. 41(4):412-415.

Thomassian A. 2005. Enfermidades dos Cavalos. $2^{\text {a }}$ ed. Varela, São Paulo.

Valentine B.A. 2006. Survey of equine cutaneous neoplasia in the Pacific Northwest. J. Vet. Diagn. Invest. 18:123-126.

White S.D. 2013. Donkey Dermatology. Vet. Clin. North Am., Equine Pract. 29(3):703-708.

White S.D. \& Yu A.A. 2006. Equine dermatology. Selected Topics in Dermatology 52:463-466. 